\title{
The Intersection of Public Policy and Health Behavior Theory in the Physical Activity Arena
}

\author{
Genevieve F. Dunton, Michael Cousineau, and Kim D. Reynolds
}

\begin{abstract}
Background: Policy strategies aimed at modifying aspects of the social, physical, economic, and educational environments have been proposed as potential solutions to the growing problem of physical inactivity. To develop effective physical activity policies in these and other areas, greater understanding of how and why policies successfully impact behavior change is needed. Methods: The current paper proposes a conceptual framework explaining how policy strategies map onto health behavior theoretical variables and processes thought to lead to physical activity change. This framework is used to make hypotheses about the potential effectiveness of different policy strategies. Results: Health behavior theories suggest that policies providing information may be particularly useful for individuals who are not yet considering or have only recently begun to consider becoming more physically active. Policies that provide opportunities may be less effective for individuals who do not find physical activity to be inherently fun and interesting. Policies that offer incentives or require the behavior may not be particularly useful at promoting long-term changes in physical activity. Conclusion: Exploring possible connections between policy strategies and theoretical constructs can help to clarify how each approach might work and for whom it may be the most appropriate to implement.
\end{abstract}

Keywords: exercise, walking, environment, psychological theories

Physical inactivity is a significant risk factor for numerous chronic diseases such as diabetes, cancer, and cardiovascular disease. ${ }^{1}$ However, only half of U.S. adults achieve recommended levels of physical activity, ${ }^{2}$ and $30 \%$ of adults reported no leisure time physical activity. ${ }^{3}$ Policy initiatives, which have been effective at combating a number of public health problems such as alcohol-related motor vehicle crashes and exposure to environmental smoke, ${ }^{4}$ are increasingly seen as a promising strategy to promote physical activity. ${ }^{5-8}$ Actions taken by government institutions through statutes, government regulations, and funded programs can create or modify physical, social, economic, and educational environments to encourage healthy behavior choices. For example, policies may subsidize transit passes, mandate schoolbased health curriculum, and change zoning regulations, building codes and street layout to increase physical activity. ${ }^{9-12}$ Despite growing interest in this area, few studies have systematically compared the effectiveness of different policy strategies to influence physical activity behavior. ${ }^{13,14}$ Consequently, little is known about which

Dunton and Cousineau are with the Dept of Preventive Medicine, University of Southern California, Alhambra, CA. Reynolds is with the School of Community and Global Health, Claremont Graduate University, Claremont, CA. policy approach is the most appropriate and when it should be implemented.

Intrapersonal theories of health behavior change may provide a guiding framework for understanding the potential effects of different policies on physical activity. The Health Belief Model, ${ }^{15,16}$ the Theory of Reasoned Action/Theory of Planned Behavior, ${ }^{17-19}$ Social Cognitive Theory, ${ }^{20,21}$ Self-Determination Theory, ${ }^{22,23}$ the Transtheoretical Model $^{24}$ describe how and the extent to which psychological, social, and environmental factors predict health behavior ${ }^{25-27}$ (see Table 1). However, researchers have not considered how established health behavior theories can be used to make predictions about the effectiveness of different policy approaches to the promotion of physical activity. To address this gap, this paper discusses the extent to which different types of policy strategies map onto variables and processes specified by key health behavior theories. It then explains how this information can be used to make hypotheses and guide research on the potential effectiveness of each policy strategy.

\section{Policy Strategies to Promote Physical Activity}

For the purpose of this paper, policies to promote physical activity are categorized into 4 primary strategies used to influence behavior (see Table 2). 
Table 1 Intrapersonal Health Behavior Theories

\begin{tabular}{lll}
\hline Health behavior theory & Constructs/variables & Description/assumptions \\
\hline $\begin{array}{l}\text { Health Belief Model } \\
\text { Perceived susceptibility, per- } \\
\text { ceived severity, perceived ben- } \\
\text { efits, perceived barriers, cues to } \\
\text { action, self-efficacy }\end{array}$ & $\begin{array}{l}\text { A person will take a health-related action if he/she feels at risk } \\
\text { for a negative health outcome (ie, perceived susceptibility and } \\
\text { severity), expects that by taking an action, he/she will prevent that } \\
\text { negative health outcome (ie, perceived benefits), and believes that } \\
\text { he/she can effectively take the action (ie, perceived barriers, self- } \\
\text { efficacy). }\end{array}$ \\
$\begin{array}{l}\text { Theory of Reasoned } \\
\begin{array}{l}\text { Action/Theory of } \\
\text { Planned Behavior }\end{array}\end{array}$ & $\begin{array}{l}\text { Attitudes, subjective norms, } \\
\text { behavioral control, behavioral } \\
\text { intention }\end{array}$ & $\begin{array}{l}\text { A person's intention to take action depends on his/her beliefs } \\
\text { about the behavior weighted by evaluations of these beliefs (ie, } \\
\text { attitudes), beliefs of other people about the behavior weighted by } \\
\text { the value attributed to these opinions (ie, subjective norms), and } \\
\text { his/her perceived ease or difficulty of taking that action (ie, per- } \\
\text { ceived behavioral control). If a person intends to take an action, } \\
\text { then it is likely that he/she will do it. }\end{array}$
\end{tabular}

Social Cognitive Theory Reciprocal determinism, environment, outcome expectancies, sonal factors (eg, beliefs), and behavior Beliefs (ie, outcome observational learning, reinforcement, self-efficacy expectancies, self-efficacy) can influence actions, and vice versa. Beliefs are molded by structures within the social and physical environment. Behavior can influence one's environment, and is determined by that environment. These processes occur through observational learning and reinforcement.

Self-Determination Theory

Transtheoretical Model
External regulation, introjected regulation, identified regulation, integrated regulation, intrinsic motivation

Stages of change, processes of change
Actions vary in the degree to which they are volitional, without any external influence. Motivation to take action occurs along a continuum from external regulation (ie, rewards, other's demands), followed by introjected regulation (ie, moral reasons), to identified regulation (ie, useful outcomes), to integrated regulation (ie, important for personal growth), to intrinsic motivation (ie, mastery, enjoyment).

People progress through 5 stages of change on the way to permanently adopting a behavior: Precontemplation, Contemplation, Preparation, Action, Maintenance. Processes of change are activities that people use to move through the stages: consciousness raising (increasing awareness), dramatic relief (emotional arousal), environmental reevaluation (social reappraisal), social liberation (environmental opportunities), self reevaluation (self reappraisal), stimulus control (reengineering), helping relationship (supporting), counter conditioning (substituting), reinforcement management (rewarding), self liberation (committing).

\section{Table 2 Policy Strategies to Promote Physical Activity}

\begin{tabular}{ll}
\hline Policy strategy & Examples \\
\hline $\begin{array}{l}\text { 1. Provide information about the } \\
\text { behavior. }\end{array}$ & $\begin{array}{l}\text { Point-of-decision stairway prompts, mass media campaigns, classroom-based } \\
\text { curriculum. }\end{array}$ \\
$\begin{array}{l}\text { 2. Increase/decrease opportunities } \\
\text { for behavior. }\end{array}$ & $\begin{array}{l}\text { Improved access, availability, and proximity to facilities, resources, services, } \\
\text { and programs; enhanced aesthetics; improved safety characteristics. }\end{array}$ \\
$\begin{array}{l}\text { 3. Offer incentives/disincentives for } \\
\text { behavior. }\end{array}$ & $\begin{array}{l}\text { Public transportation vouchers, lottery incentives for active commuting, tax } \\
\text { deductions physical activity programs or supplies, reduced health insurance } \\
\text { premiums. }\end{array}$ \\
4. Require/prohibit behavior. & Pedestrian-only streets, driving restrictions, parking regulations.
\end{tabular}


1. Provide Information About the Behavior. Policies can promote physical activity by providing information about the benefits and risks of health and unhealthy behaviors such as community-wide education and mass media campaigns ${ }^{28-31}$ (eg, CDC VERB campaign $\left.{ }^{32,33}\right)$ and classroom-based physical activity curriculum..$^{34-36}$

2. Increase/Decrease Opportunities for Behavior. Another strategy that policies may use is to increase opportunities for physical activity or decrease opportunities for inactive behavior such as improved access, availability, and proximity to facilities, resources, services, and programs. Examples include the creation of safer routes to school, ${ }^{37}$ improvements in street lighting, ${ }^{38}$ the addition of bike lanes and planted trees, ${ }^{39}$ and changes in school-based physical education programs. ${ }^{40}$ These types of policies may also improve aesthetics and safety characteristics of environments for physical activity. ${ }^{41}$

3. Provide Incentives/Disincentives for Behavior. The provision of incentives or disincentives for behavior is another strategy through which policies can influence physical activity. These policies offer rewards and savings for engaging in active behaviors or impose fines and fees for engaging in inactive behaviors. In a recent paper, Pratt and colleagues ${ }^{12}$ suggest a number of different ways that economic incentives can be used to promote physical activity such as taxing electronic sedentary equipment, tax credits for the purchase of health club membership, increasing the gas tax, and parking cash outs (ie, employees given cash value of parking space). Interventions based upon this strategy have also distributed transportation passes to employees ${ }^{42}$ and offered lottery incentives for activity. ${ }^{43}$

4. Require/Prohibit Behavior. Physical activity policies may also require active behaviors or prohibit inactive behaviors through regulations, requirements, restrictions, and prohibitions enforced through government-agencies and the courts. Some examples of environmental modification resulting from this type of policy include streets with limited car access, parking regulations, and skateboarding restrictions. Empirical studies examining the effects of this type of policy enactment on physical activity are limited. However, examples of policies that successfully require/prohibit behaviors are evident in the area of tobacco control (eg, indoor smoking restrictions, age requirements for the purchase of tobacco).$^{4-46}$

\section{Proposed Relationships Between Policy Strategies and Theoretical Constructs}

To date, there is little research about which type of policy strategy is the most effective approach for increasing physical activity at the population level. However, considering the variables proposed by intrapersonal health behavior theories (see Table 1) can make the selection of the right policy for a given population and setting more likely and may save time and money in the long run. To better understand which policy strategy will the most effective and when it should be implemented, it may be helpful to consider the intervening theoretical processes that link the policy to behavior. To address this gap, this paper discusses the extent to which each of the 4 outlined physical activity policy strategies map onto theoretical components. Figure 1 shows a proposed conceptual model connecting policy strategies, theoretical constructs, and physical activity. The following sections will further elaborate on this model by describing hypothesized linkages between each policy strategy and specific theoretical variables.

\section{Provide Information About the Behavior}

Policies that seek to promote physical activity by providing health information rely heavily on cognitive and motivational processes such as attitude and belief change (see Table 3). Community-wide media campaigns consisting of billboard, newspaper, radio, and poster advertisements have been shown to influence perceived benefits (ie, outcomes of walking) ${ }^{47}$ and perceived susceptibility (ie, concerns about cardiovascular health), ${ }^{48}$ which are important components of the Health Belief Model and Social Cognitive Theory (see Table 1). Likewise, mass media campaigns have been found to affect Theory of Reasoned Action/Theory of Planned Behavior constructs such as attitudes ${ }^{49,50}$ and intentions to engage in physical activity $^{51}$ (see Table 1). Policies that provide information about the health benefits of physical activity may tap into underlying needs for personal growth and self-improvement, which can be seen as a form of internally-oriented

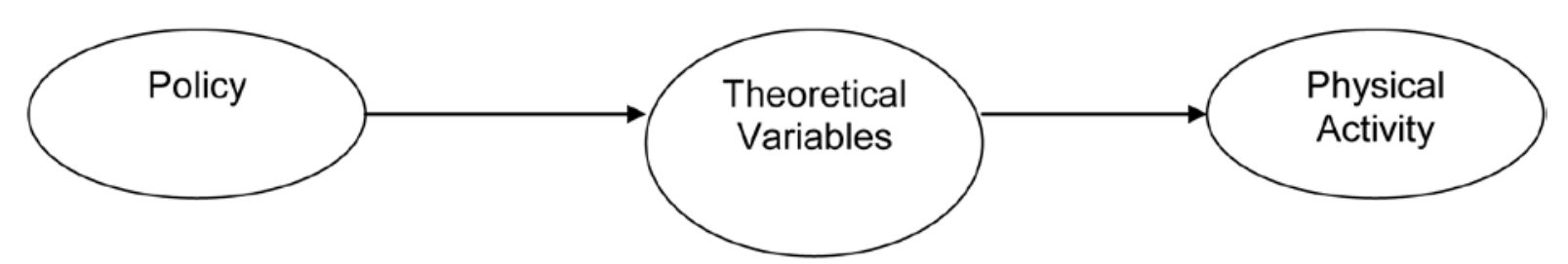

Figure 1 - Proposed linkages between policy, theoretical variables, and physical activity. 
Table 3 Proposed Relationships Between Policy Strategies for Promoting Physical Activity and Health Behavior Theoretical Variables

\begin{tabular}{|c|c|c|c|c|}
\hline \multirow[b]{2}{*}{$\begin{array}{l}\text { Health behavior } \\
\text { theory }\end{array}$} & \multicolumn{4}{|c|}{ Policy strategy } \\
\hline & $\begin{array}{l}\text { Provide information } \\
\text { about the behavior }\end{array}$ & $\begin{array}{l}\text { Increase/decrease } \\
\text { opportunities for } \\
\text { the behavior }\end{array}$ & $\begin{array}{l}\text { Offer incentives } \\
\text { or disincentives } \\
\text { for the behavior }\end{array}$ & $\begin{array}{l}\text { Require/prohibit } \\
\text { the behavior }\end{array}$ \\
\hline Health Belief Model & $\begin{array}{l}\text { Perceived susceptibility, } \\
\text { perceived severity, } \\
\text { perceived benefits }\end{array}$ & $\begin{array}{l}\text { Perceived barriers, cues to } \\
\text { action }\end{array}$ & $\begin{array}{l}\text { Perceived benefits, cues to } \\
\text { action }\end{array}$ & None \\
\hline $\begin{array}{l}\text { Theory of Reasoned } \\
\text { Action /Theory of } \\
\text { Planned Behavior }\end{array}$ & $\begin{array}{l}\text { Attitudes toward the } \\
\text { behavior, outcome } \\
\text { expectancies }\end{array}$ & $\begin{array}{l}\text { Social norms, perceived } \\
\text { behavioral control }\end{array}$ & $\begin{array}{l}\text { Attitudes toward the behavior, } \\
\text { outcome expectancies }\end{array}$ & None \\
\hline $\begin{array}{l}\text { Social Cognitive } \\
\text { Theory }\end{array}$ & Outcome expectancies & $\begin{array}{l}\text { Environment, social model- } \\
\text { ing, self-efficacy }\end{array}$ & $\begin{array}{l}\text { Outcome expectancies, rein- } \\
\text { forcement }\end{array}$ & Reciprocal determinism \\
\hline $\begin{array}{l}\text { Self-Determination } \\
\text { Theory }\end{array}$ & Integrated regulation & Intrinsic regulation & External regulation & $\begin{array}{l}\text { External regulation, } \\
\text { introjected regulation }\end{array}$ \\
\hline $\begin{array}{l}\text { Transtheoretical } \\
\text { Model }\end{array}$ & $\begin{array}{l}\text { "Consciousness } \\
\text { raising"- } \\
\text { Precontemplation to } \\
\text { Contemplation }\end{array}$ & $\begin{array}{l}\text { "Stimulus } \\
\text { control"-Preparation to } \\
\text { Action and Maintenance }\end{array}$ & $\begin{array}{l}\text { "Reinforcement } \\
\text { management"-- } \\
\text { Action to Maintenance }\end{array}$ & $\begin{array}{l}\text { "Social liberation"- } \\
\text { Maintenance }\end{array}$ \\
\hline
\end{tabular}

motivation for behavior change (eg, introjected motivation) according to Self-Determination Theory (see Table 1). In addition, policies that provide information about the behavior can be thought of as a form of consciousness raising, a process of change that involves increasing knowledge and awareness, which according to the Transtheoretical Model is thought to stimulate movement between the earlier stages of change, ${ }^{52}$ particularly from precontemplation to contemplation (see Table 1). Overall, research showing that beliefs, attitudes, and motives are predictive of physical activity ${ }^{53,54}$ offers support for potential effectiveness of information-based policies to change physical activity patterns.

\section{Increase/Decrease Opportunities for Behavior}

Policies can increase opportunities for physical activity by modifying environmental and contextual factors, which in turn, may influence perceived barriers, selfefficacy, social norms, intrinsic motivation, and stimulus control (see Table 3). Creating opportunities for physical activity can reduce perceived barriers to behavior, which is an important component of the Health Belief Model ${ }^{55}$ (see Table 1). In addition, according to Social Cognitive Theory, overcoming situational barriers may positively impact self-efficacy. ${ }^{21}$ For example, research has shown that increased opportunities for school-based physical activity can enhance self-efficacy among youth. ${ }^{56,57}$ Poli- cies that provide opportunities for physical activity may influence social norms, which maps onto the Theory of Planned Behavior (see Table 1). Environmental changes such as building a bike trail may influence an individual's thinking that physical activity is becoming normative, acceptable and even desirable. Further, increasing opportunities for physical activity can augment one's enjoyment of that behavior - a form of internal motivation (ie, intrinsic motivation) described by Self-Determination Theory (see Table 1). For example, developing a park or multiuse trail in a natural area that is rich in vegetation and wildlife can make physical activity more pleasant and fun for those who use that facility or attract new people who enjoy these features. ${ }^{58,59}$ Lastly, policies that increase opportunities for physical activity can serve as "stimulus controls" (according to the Transtheoretical Model) because they restructure the environment so that people interact with stimuli that encourage active behaviors (eg, parks, recreational facilities). ${ }^{52}$ The Transtheoretical Model suggests that stimulus controls influence progression between the later stages of change, particularly from the action to maintenance stages $^{52}$ (see Table 1). In summary, there is substantial theoretical support for the potential effectiveness of policies that increase opportunities for physical activity.

Provide Incentives/Disincentives for Behavior. Health behavior theories describe how policies providing incentives or disincentives may be used to change physical activity behavior. Self-Determination Theory 
suggests that offering rewards or punishments for behavior triggers externally-oriented motivation (ie, external regulation; see Table 1). Although external rewards may induce change for simple behaviors such as seat belt use ${ }^{60}$ less evidence exists for their capacity to promote long-term behavior change, and they are believed to undermine intrinsic motivation (eg, fun and enjoyment). ${ }^{61}$ When considering this policy strategy in light of the Transtheoretical Model's processes of change, providing incentives for behavior change could be considered a form of "reinforcement management." Rewards for the physical activity are received after the behavior has already been initiated and hence they are expected to be the most helpful in stimulating progress from the action to the maintenance stage ${ }^{52}$ (see Table 1). Furthermore, policies that provide incentives are likely to change expected outcomes, perceived benefits and attitudes toward the behavior, which are elements of the Health Belief Model, Theory of Reasoned Action, Theory of Planned Behavior, and Social Cognitive Theory. However, they are unlikely to influence behavior alone, without the other important constructs in those models being affected.

Require/Prohibit the Behavior. Health behavior theories also describe possible mechanisms through which policies that require or prohibit behavior may promote physical activity (see Table 3 ). According to Self-Determination Theory, strategies that restrict behavioral choice represent external and introjected forms of regulation (see Table 1). For example, policies may increase levels of walking by banning the use of motorized vehicles in certain settings (eg, college campuses, shopping malls, places of employment). The motivation for physical activity on pedestrian-only streets is based on the desire to comply with external forces (ie, rules and requirements) and avoid negative repercussions. While pedestrian-only streets may eliminate behavioral options, other rule-based policies to promote physical activity may merely constrain them. For example, if parking at a workplace or school is limited, people can choose to walk, bicycle, or ride public transit as an alternative. In these situations, external motivation still plays a role by initially restricting behavioral options, however, these policies require a new set of decisions that may be guided by a variety of other psychosocial processes (eg, behavioral enjoyment, monetary incentives, etc). In terms of the Transtheoretical Model's processes of change, policies that require/prohibit behaviors could be considered a form of "social liberation" because they increase opportunities for the targeted health behavior in society. ${ }^{52}$ These policies might be most widely accepted among individuals who have already progressed into the maintenance stage ${ }^{52}$ and consequently, tend to look favorably upon society's actions to further support their behavior. For individuals in the earlier stages of change, policies that require active behaviors in certain settings could have negative consequences. For example, individuals who encounter situations that require more walking than expected could experience pain or injury from improper footwear and carrying heavy loads (eg, shopping bags, backpacks). In addition, reactance could occur. Individuals who are frequently required to walk in one setting (eg, university campus) may be less compelled to engage in volitional physical activity in other settings (eg, gym/health club) due to fatigue and the generation of negative attitudes toward the behavior. Further, people may have limits on the time they budget to overall physical activity. Time spent in required walking may reduce the time available for leisure-time physical activity. Policies that require or prohibit behavior map onto Social Cognitive Theory in the general sense of reciprocal determinism. ${ }^{20}$ The environment interacts with and shapes the options at the personal and behavioral levels. Policies that require or prohibit behaviors to promote physical activity do not closely adhere to the constructs proposed by other intrapersonal health behavior theories such as the Health Belief Model, Theory of Reasoned Action, and Theory of Planned Behavior.

\section{Summary and Discussion}

Exploring possible connections between policy strategies and theoretical constructs can help to clarify how each approach might work and for whom it may be the most appropriate to implement. The sizable body of research showing that changing attitudes and beliefs predict behavior ${ }^{53,54}$ provides support for potential effectiveness of information-based policies (eg, point-of-decision prompts, school-based curriculum) to promote physical activity. The processes of change component of the Transtheoretical model suggests that policies that provide information may be particularly useful for individuals who are not yet considering or have only recently begun to consider becoming more physically active. Policies that seek to promote physical activity by providing opportunities (eg, facilities, programs, equipment) for the behavior rely heavily upon intrinsic motivation to be active in those settings, and therefore may less useful for individuals who do not find physical activity to be inherently fun and interesting. Policies that provide opportunities may also be especially effective for individuals who have recently adopted a regular physical activity routine, and are searching for methods of maintaining this behavior over time. On the other hand, policies that offer incentives or require the behavior do not involve many psychosocial processes other than external motivation and therefore, may not be particularly useful at promoting long-term changes in physical activity unless they are pervasive (eg, implemented across multiple settings) and permanent.

\section{Recommendations for Research and Policy}

Identifying key theoretical constructs influenced by a policy can inform the public policy selection and formation process (ie, decisions among a set of competing policies that are being considered). For example, theory suggests that policies that provide incentives may not 
sustain behavior change. Therefore, policies that offer monetary benefits may not be the best choice when long-term maintenance of behavior change in desired. Furthermore, intrapersonal health behavior theories can enlighten policy-makers about when policies should target population subgroups. For example, policies mapping onto processes of change specified by the Transtheoretical Model (eg, consciousness raising, stimulus control) can have differential effectiveness depending on whether the population subgroup has considered or attempted behavior change. The health behavior theories considered in this paper focus primarily on individual level behavior change. It is possible that policies also influence collective action, ${ }^{62,63}$ which can in turn, influence individual behavior and/or the passage of additional policies in this area. Collective action theory adds to the complexity in understanding the impact of social policies on health behavior and vice versa. Overall, the goal of current paper was to initiate a discussion on we can use health behavior theory to guide research and decisions in the physical activity policy arena. As such, it is intended to serve as a launching point for future work on this topic.

\section{Conclusions}

A systematic examination of the intersection between public policy and health behavior theory in the physical activity arena suggests that the implementation of a single policy strategy may be insufficient on its own to produce sustained behavior change. Instead, it may be necessary to simultaneously execute policies that offer opportunities for physical activity with those that provide information. In that way, individuals can be aware of the benefits of using the facilities and resources that are available. Lastly, policies that offer incentives or require behavior may not provide the best solution for producing lasting behavior change among inactive individuals. However, they may be helpful for reinforcing and supporting physical activity among individuals who have recently adopted the behavior or are working to maintain an active lifestyle.

\section{Acknowledgments}

The first author was supported by the Cancer Prevention Fellowship Program, Office of Preventive Oncology, National Cancer Institute, National Institutes of Health during the preparation of this paper.

\section{References}

1. McKenna MT, Taylor WR, Marks JS, Koplan JP. Current issues and challenges in chronic disease control. In: Brownson RC, Remington PL, Davis JR, eds. Chronic Disease Epidemiology and Control. 2nd ed. Washington: American Public Health Association; 1998.
2. Schiller JS, Martinez M, Hao C, Barnes P. Early release of selected estimates based on data from the January-September 2004 National Health Interview Survey. National Center for Health Statistics. http://www.cdc.gov/nchs/nhis. htm. March 2005.

3. Barnes PM, Shoenborn CA. Physical Activity Among Adults: United States, 2000, No. 333. Hyattsville, MD: United States Department of Health and Human Services, Centers for Disease Control and Prevention, National Center for Health Statistics; 2003.

4. Mensah GA, Goodman RA, Zaza S, Moulton AD, Kocher PL, Dietz WH, et al. Law as a tool for preventing chronic diseases: expanding the spectrum of effective public health strategies. Prev Chronic Dis [serial online]. 2004.

5. Murkowski L. Preventing obesity in children: the time is right for policy action. Am J Prev Med. 2007;33:S167S168.

6. King AC, Jeffrey RW, Fridinger F, et al. Environmental and policy approaches to cardiovascular disease prevention through physical activity: issues and opportunities. Health Educ Q. 1995;22:499-511.

7. Schmid TL, Pratt M, Howze E. Policy as intervention: environmental and policy approaches to the prevention of cardiovascular disease. Am J Public Health. 1995;85:1207-1211.

8. CDC. Increasing physical activity. A report on recommendations of the Task Force on Community Preventive Services. MMWR. 2001;50(RR-18):1-16.

9. Sallis JF, Cervero RB, Asher W, Henderson KA, Kraft MK, Kerr J. An ecological approach to creating active living communities. Annu Rev Public Health. 2006;27:297-322.

10. Hayne CL, Moran PA, Ford MM. Regulating environments to reduce obesity. J Public Health Policy. 2004;25:391407.

11. Heath GW, Brownson RC, Kruger J, et al. The effectiveness of urban design and land use and transportation policies and practices to increase physical activity: a systematic review. J Phys Act Health. 2006;3:S55-S76.

12. Pratt M, Macera CA, Sallis JF, O'Donnell M, Frank LD. Economic interventions to promote physical activity: application of the SLOTH model. Am J Prev Med. 2004;27:136-145.

13. Wendel-Vos W, Droomers M, Kremers S, Brug J, van Lenthe F. Potential environmental determinants of physical activity in adults: a systematic review. Obes Rev. 2007;8:425-440.

14. Anderson ES, Wojcik JR, Winett RA, Williams DM. Social-cognitive determinants of physical activity: the influence of social support, self-efficacy, outcome expectations, and self-regulation. Health Psychol. 2006;25:510520.

15. Rosenstock I. Historical origins of the Health Belief Model. Health Educ Monogr. 1974;2:328-335.

16. Janz NK, Champion VL, Strecher VJ. The Health Belief Model. In: Glanz K, Lewis FM, Rimer BK, eds. Health Behavior and Health Education. San Francisco, CA: Jossey-Bass Publishers; 2002:45-66. 
17. Ajzen I, Fishbein M. Understanding Attitudes and Predicting Social Behavior. Englewood Cliffs, NJ: Prentice-Hall; 1980.

18. Fishbein M, Ajzen I. Belief, Attitude, Intention, and Behavior: An Introduction to Theory and Research. Reading, MA: Addison-Wesley; 1975.

19. Ajzen I. The theory of planned behavior. Organ Behav Hum Decis Process. 1991;50:179-211.

20. Bandura A. Social Foundations of Thought and Action. Englewood Cliffs, NJ: Prentice Hall; 1986.

21. Bandura A. Self-efficacy: The Exercise of Control. New York: Freeman; 1997.

22. Deci EL, Ryan RM. Intrinsic Motivation and Self-Determination in Human Behavior. New York: Plenum; 1985.

23. Ryan RM, Deci EL. Self-determination theory and the facilitation of intrinsic motivation, social development, and well-being. Am Psychol. 2000;55:68-78.

24. Prochaska JO, DiClemente CC. Stages and processes of self-change of smoking: toward an integrative model of change. J Consult Clin Psychol. 1983;51:390-395.

25. Hochbaum GM, Sorenson JR, Lorig K. Theory in health education practice. Health Ed Quar. 1992;19:295-313.

26. Lewis BA, Marcus BH, Pate RR, Dunn AL. Psychosocial mediators of physical activity behavior among adults and children. Am J Prev Med. 2002;23:26-35.

27. Glanz K. Perspectives on Using Theory. In: Glanz K, Lewis FM, Rimer BK, eds. Health Behavior and Health Education. San Francisco, CA: Jossey-Bass Publishers; 2002:545-558.

28. Bauman A, Armstrong T, Davies J, et al. Trends in physical activity participation and the impact of integrated campaigns among Australian adults, 1997-99. Aust N Z J Public Health. 2003;27:76-79.

29. Jason LA, Greiner BJ, Naylor K, Johnson SP, Van Egeren L. A large-scale, short-term, media-based weight loss program. Am J Health Promot. 1991;5:432-437.

30. Reger-Nash B, Fell P, Spicer D, et al. Walks: replication of a communitywide physical activity campaign. Prev Chronic Dis. 2006;3:A90.

31. Wray RJ, Jupka K, Ludwig-Bell C. A community-wide media campaign to promote walking in a Missouri town. Prev Chronic Dis. 2005;2:A04.

32. Huhman M, Bauman A, Bowles HR. Initial outcomes of the VERB Campaign: tweens' awareness and understanding of campaign messages. Am J Prev Med. 2008;34:S241-S248.

33. Price SM, Huhman M, Potter LD. Influencing the parents of children Aged 9-13 years: findings from the VERB Campaign. Am J Prev Med. 2008;34:S267-S274.

34. Verstraete SJ, Cardon GM, De Clercq DL, De Bourdeaudhuij IM. A comprehensive physical activity promotion program at elementary school: the effects on physical activity, physical fitness and psychosocial correlates of physical activity. Public Health Nutr. 2007;10:477-484.

35. Hortz B, Petosa R. Impact of the "Planning to be Active" leisure time physical exercise program on rural high school students. J Adolesc Health. 2006;39:530-535.
36. Belansky ES, Romaniello C, Morin C, et al. Adapting and implementing a long-term nutrition and physical activity curriculum to a rural, low-income, biethnic community. $J$ Nutr Educ Behav. 2006;38:106-113.

37. Boarnet MG, Anderson CL, Day K, McMillan T, Alfonzo M. Evaluation of the California Safe Routes to School Legislation: Urban form changes and children's active transportation to school. Am J Prev Med. 2005;28:134-140.

38. Painter K. The influence of street lighting improvements on crime, fear and pedestrian street use, after dark. Landsc Urban Plan. 1996;35:193-201.

39. Macbeth AG. Bicycle lanes in Toronto. ITE Journal. 1999;69:38-46.

40. Kahn EB, Ramsey LT, Brownson RC, et al. The effectiveness of interventions to increase physical activity. A systematic review. Am J Prev Med. 2002;22:73-107.

41. Humpel N, Owen N, Leslie E. Environmental factors associated with adults' participation in physical activity: A review. Am J Prev Med. 2002;22:188-199.

42. Lachapelle U, Frank LD. Transit and health: mode of transport, employer-sponsored public transit pass programs, and physical activity. J Public Health Policy. 2009;30:S73-S94.

43. Vuori IM, Oja P, Paronen O. Physically active commuting to work-testing its potential for exercise promotion. Med Sci Sports Exerc. 1994;26:844-850.

44. Albers AB, Siegel M, Cheng DM, Rigotti NA, Biener L. Effects of restaurant and bar smoking regulations on exposure to environmental tobacco smoke among Massachusetts adults. Am J Public Health. 2004;94:1959-1964.

45. Brownson RC, Hopkins DP, Wakefield MA. Effects of smoking restrictions in the workplace. Annu Rev Public Health. 2002;23:333-348.

46. Luke DA, Stamatakis KA, Brownson RC. State youthaccess tobacco control policies and youth smoking behavior in the United States. Am J Prev Med. 2000;19:180-187.

47. O’Donnell M. What works best? Knowledge, skills, motivation, and opportunity. Am J Health Promot. 2005;19:Suppl 1-7 following 84, iii, 2005 Sep-Oct.

48. Meyer AJ, Nash JD, McAlister AL, Maccoby N, Farquhar JW. Skills training in a cardiovascular health education campaign. J Consult Clin Psychol. 1980;48:129-142.

49. Beaudoin CE, Fernandez C, Wall JL, Farley TA. Promoting healthy eating and physical activity short-term effects of a mass media campaign. Am J Prev Med. 2007;32:217-223.

50. Cavill N, Bauman A. Changing the way people think about health-enhancing physical activity: do mass media campaigns have a role? J Sports Sci. 2004;22:771-790.

51. Owen N, Bauman A, Booth M, Oldenburg B, Magnus P. Serial mass-media campaigns to promote physical activity: reinforcing or redundant? Am J Public Health. 1995;85:244-248.

52. Prochaska JO, DiClemente CC, Norcross JC. In search of how people change. Applications to addictive behaviors. Am Psychol. 1992;47:1102-1114. 
53. Williams DM, Anderson ES, Winett RA. A review of the outcome expectancy construct in physical activity research. Ann Behav Med. 2005;29:70-79.

54. Van Der Horst K, Paw MJ, Twisk JW, Van Mechelen W. A brief review on correlates of physical activity and sedentariness in youth. Med Sci Sports Exerc. 2007;39:12411250.

55. Rosenstock, I. M. Why people use health services. Milbank Mem Fund Q. 1966:44:94ff.

56. Dishman RK, Motl RW, Saunders R, et al. Self-efficacy partially mediates the effect of a school-based physicalactivity intervention among adolescent girls. Prev Med. 2004;38:628-636.

57. Edmundson E, Parcel GS, Feldman HA, et al. The effects of the Child and Adolescent Trial for Cardiovascular Health upon psychosocial determinants of diet and physical activity behavior. Prev Med. 1996;25:442-454.
58. Anderson TK, Stodolska M, Shinew K J, Gobster P. Environmental preferences and the use of natural areas for physical activity among Hispanic residents. Prepared for the United States Department of Agriculture - Forest Service; North Central Research Station - Unit 4902. 2006.

59. DeLucio JV, Múgica M. Landscape preferences and behaviour of visitors to Spanish national parks. Landsc Urban Plan. 1994;29:145-160.

60. Elman D, Kelebrew TJ. Incentives and seat belts: changing a resistant behavior through extrinsic motivation. J Appl Soc Psychol. 2006;8:72-83.

61. Eisenberger R, Cameron J. Detrimental effects of reward: reality or myth? Am Psychol. 1996;51:1153-1166.

62. Blumer H. Collective Behavior. In: Lee AM, ed. Principles of Sociology. New York: Barnes \& Noble; 1951:67-121.

63. Staggenborg S. Social Movements. Oxford, UK: Oxford University Press; 2008. 